\title{
Sound production in four species of the Loricariidae family
}

\author{
Tellechea, JS. ${ }^{a}$, Teixeira-De-Mello, $F^{b}{ }^{b}$ Gonzalez-Bergonzoni, $I^{c}{ }^{c}$ and Vidal, $N .^{c}$ \\ ${ }^{a}$ Laboratorio de Fisiología de la Reproducción y Ecología de Peces, Facultad de Ciencias, Universidad de la República, \\ Montevideo, Uruguay. \\ ${ }^{b}$ Grupo de Ecología y Rehabilitación de Sistemas Acuáticos, Departamento de Ecología y Evolución, Facultad de \\ Ciencias, Maldonado, Uruguay \\ 'Department of Bioscience, Aarhus University, Vejlsøvej 25, 8600 Silkeborg, Denmark \\ *e-mail: jstellechea@gmail.com
}

Received September 4, 2012 - Accepted September 17, 2012 - Distributed August 31, 2013

Many fish species use acoustic signals for a variety of purposes (Lobel, 2002). One application of bioacoustics is the use of passive acoustic technology to record temporal and spatial patterns of fish reproduction by detecting sounds associated with spawning (Lobel \& Mann, 1995) and other behaviors associated with disturbance (Tellechea et al., 2011).

This paper documents, for the first time, sound production by four species, Hypostomus commersoni $(\mathrm{n}=3)$, Hypostomus derbyi $(\mathrm{n}=2)$, Paraloricaria vetula $(\mathrm{n}=2)$ and Ricola macrops $(\mathrm{n}=2)$ from the Uruguay River in Uruguay, South America. To our knowledge, there are no studies in the region on sound production by Loricariidae fish species. This family of catfish (Order Siluriformes), typical of South American freshwater habitats (Nelson, 2006), consists of almost 700 species and new species are described every year.

Fish were collected with a multi-mesh net in April 2008 at three sites on the Lower Uruguay River, Uru- guay. The specimens were maintained live in $300 \mathrm{~L}$ tanks with river water at a temperature ranging from 15 to $17^{\circ} \mathrm{C}$, as measured at the collection site. Each fish was captured with a hand net and placed at a $1 \mathrm{~m}$ distance from the underwater hydrophone in a separate $50 \mathrm{~L}$ tank for recording. After each recording, fish were sacrificed with an overdose of anesthesia (solution of 2-PhenoxyEthanol, $1 \mathrm{~mL} \mathrm{~L}^{-1}$ ). Total length (TL) in $\mathrm{cm}$ and sex were also determined.

Recordings were made with a hydrophone built in the laboratory (sensitivity-40 dB re: $1 \mu \mathrm{Pa}$ and linear from $20 \mathrm{~Hz}$ and $60 \mathrm{kHz}$ ) on a digital recorder TASCAM HD-P2, with a sampling frequency of $44.1 \mathrm{kHz}$. Sound analysis was performed using Audacity free software, version 1.2.3. Power spectra were calculated using a 1024-point Fast Fourier Transform (FFT) with a Hanning window. The four species emitted sound, as a disturbance call produced by the teeth, when fishes were immobilized underwater with the hand or outside the water.
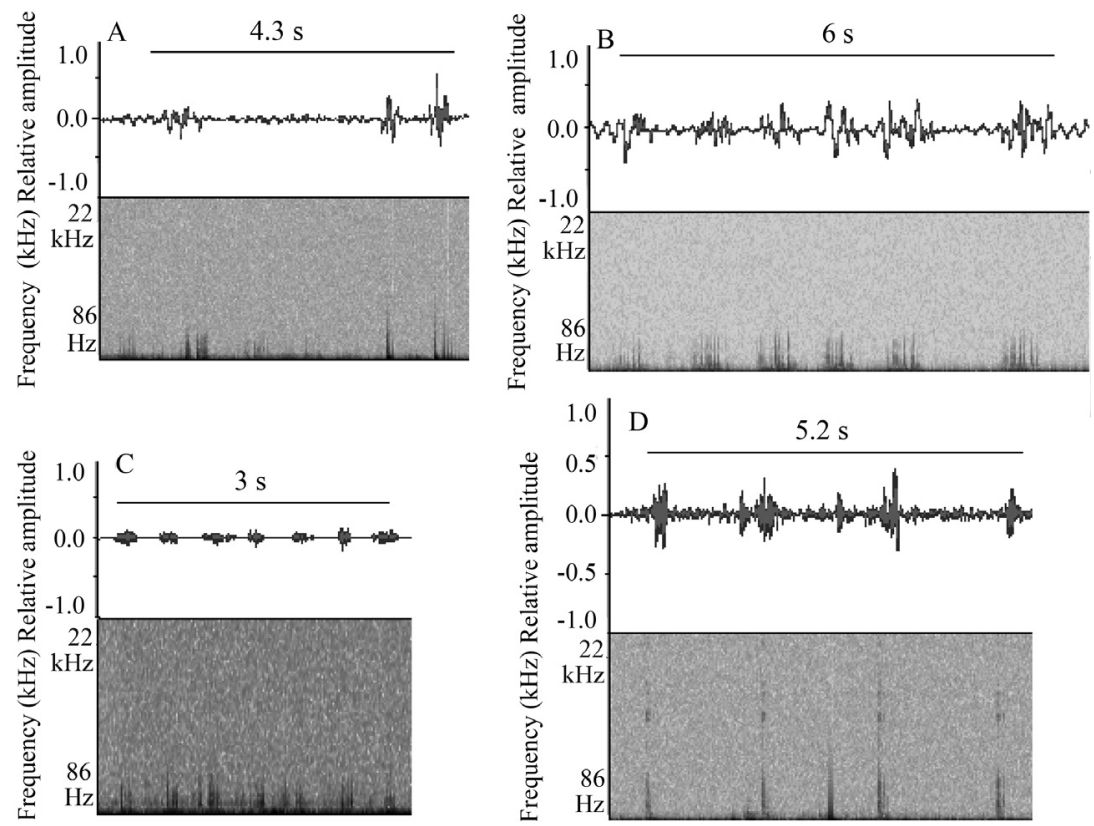

Figure 1 - Oscillogram and sonograms using the hamming window function and an FFT size of 1024 points (Audacity software). A) H. commersoni dominant frequency, DF $348 \mathrm{~Hz}$. B) H. derbyi, DF $292 \mathrm{~Hz}$. C) $P$. vetula, DF $389 \mathrm{~Hz}$. D) $R$. macrops, DF $200 \mathrm{~Hz}$. 
H. commersoni produced a series of 5 to 10 pulses, with a duration of $26 \pm 0.95 \mathrm{~ms}$, interval and dominant frequency of $350 \pm 5.10 \mathrm{~Hz}$ (Figure 1a). H. derbyi produced a series of a series of 4 to 8 pulses, with a duration of $28 \pm 2.02 \mathrm{~ms}$ and a dominant frequency of $29 \pm 4.64$ $\mathrm{Hz}$ (Figure 1b). P. vetula also produced a series of pulses of 5 to 14 pulses with a duration of $30 \pm 0.22 \mathrm{~ms}$ and a dominant frequency of $390 \pm 3.23 \mathrm{~Hz}$ (Figure 1c). The third species $R$. macrops produced a series of 3 to 11 pulses, with a duration and dominant frequency of 20 $\pm 0.12 \mathrm{~ms}$ and $200 \pm 6.08 \mathrm{~Hz}$, respectively (Figure 1d).

Disturbance calls produced by fish in the Sciaenid family appear to indicate fright, alarm, pain, distress, or a similar state (Fish \& Mowbray, 1970; Fine et al., 2004). Sorensen (1895) hypothesized that pectoral stridulation in South American catfishes could alert predators to the spine, and therefore Kaatz (1999) suggested that these sounds may have an aposematic function (Tellechea et al., 2011). The same behavior may be displayed by these species studied here as they have spines on their plates. This implies that disturbance calls could provide some evolutionary advantage as well. Disturbance calls in this family may have evolved as a behavior for defense or as an agony call to warn of danger. Future studies on the behavior of these species are necessary to understand the role of sound production.

\section{References}

FINE, ML., SCHRINEL, J. and CAMERON, T.M., 2004. The effect of loading on disturbance sounds of the Atlantic croaker Micropogonius undulatus: air vs. water. Journal of the Acoustical Society of America, vol. 116, no. 2, p. 1271-1275.

FISH, MP. and MOWBRAY, WH., 1970. Sounds of the Western North Atlantic Fishes. Baltimore: Johns Hopkins Press.

KAATZ, IM., 1999. The Behavioral and Morphological Diversity of Sound Communication Systems in a Clade of Tropical Catfishes, with Comparison to Ten Additional Acoustic Catfish Families (Order Siluriformes, Superfamily Aroidei). Syracuse, NY: State University of New York. Ph.D. Dissertation.

LOBEL, PS., 2002. Diversity of fish spawning sound and the application of passive acoustic monitoring. Bioacoustics: The international Journal of Animal Sound and its Recording. Vol. 12, no. 2-3, p. 286-289.

LOBEL, PS. and MANN, DA., 1995. Spawning sounds of the domino damselfish, Dascyllus albisella (Pomacentridae), and the relationship to male size. Bioacoustics, vol. 6, p. 199-213.

NELSON, JS., 2006. Fishes of the World. New York: John Wiley \& Sons.

SORENSEN, W., 1895. Are the extrinsic muscles of the airbladder in some Siluroidae, and the elastic spring apparatus of others subordinate to the voluntary production of sounds? Journal of Anatomy and Physiology, vol. 29, p. 109-139.

TELLECHEA, JS., TEIXEIRA DE MELLO, F., GONZALEZBERGONZON, I. and VIDAL, N., 2011. Distress call and spine locking in Neotropical catfish (Iheringichthys labrosus - Pimelodidae), from Uruguay river, South America. Neotropical Ichthyology, vol. 9, no. 4, p. 889-894. 